\title{
Introduction: From colonial past to global reality
}

One of the most striking features of our times is the ongoing presence of the past in economic and social matters. Nations grow and develop, but some of their main characteristics remain closely connected with their original economic and social formation. Even more striking, the characteristics of the areas or regions that suffered the consequences and felt the power of the most powerful economic structures tend to disseminate, affecting other regions and eventually the whole world. This kind of 'adverse selection' between countries and their economic structures, both developed and underdeveloped, is one of the main focuses of interest of this book.

The countries in which economic power has been historically most concentrated and consolidated are former European colonies in South America and Asia. In those countries, economic power is a phenomenon that is historically part of society and, therefore, much easier to identify. This statement is not new, but its consequences for the economics and internal legal systems in place in developing countries were disregarded in the past and are still belittled.

There is no doubt that in former colonies, economic power was made up of economic relationships that were relevant factors even for the formation of the national states. The histories of most, if not all, of these countries are tightly intertwined with monopolistic colonization, either as state monopolies (Latin America) or publicprivate monopolies (the 'Indian companies' of south-east Asia). This is an important element to be noted. The status of 'colony', far beyond external dependence, created internal power structures that marked and still influence many aspects of development (or underdevelopment) in these societies.

This is why it appears possible to revisit their development processes, starting from the structures of economic power and the structures of income distribution that follow them. The bonds of colonial dependence that motivated underdevelopment, even if the 
root cause, are not its ultimate cause. The explanation is simple, but must be well understood. The internal economic structures are what permit or inhibit, in the necessary moments, the breakthrough from external economic dependency. As we all know, this rarely took place in the history of developing countries. Apart from rare and exceptional situations, in these countries the bonds of dependency are rarely counterattacked and even less frequently broken. This is because of internal power structures and income distribution that benefits, even if indirectly, from these bonds.

It is therefore on these structures that the analysis should be focused. In addition, the relationship between economic power and income distribution must be addressed in the light of historic evidence. This relationship is intense.

Traditional analysis tends to identify only one economic consequence of monopoly structures: its draining power on consumers, essentially identifying it as the value of the monopolist's extraordinary profit, which is extracted from consumers through the imposition of monopolistic prices. As has been shown in empirical studies, this value may not be dismissed and accounts for a relevant portion of income concentration.

The fact is that this relationship between economic concentration and income distribution is much deeper and more extensive. This is especially true of structurally concentrated economies such as the former colonies. On the one hand, the relationship is more extensive in the products market, affecting industrial organization itself. As well as the imbalance in relations between consumers and manufacturers, with the consequent inefficiencies in allocation and distribution, it leads to an absolute disproportion among economic sectors. The dynamic sector of the economy since colonial times is generally concentrated in primary products or low-technology manufactured goods for export and in the durable consumer goods to be consumed internally by the higher income segments of the population. These two sectors, monopolized or oligopolized, concentrate inversions and productivity gains. They therefore drain resources from the economic system either directly, through monopolistic profits obtained from suppliers, or indirectly, via the siphoning of investments that would otherwise be invested in other sectors (hereafter called peripheral economic sectors).

The effects are also deeper. As well as the consumer market and peripheral economic sectors, there is also strong interference in the 
labour market. Thus, in many, if not most, of these countries, income concentration ends up becoming a fundamental condition for economic growth. This is precisely because, based on the production of primary products and simple raw materials, be it for the domestic or foreign market, productivity gains in these economies cannot be obtained only through technological improvements (which are at times insufficient in such low-technology sectors). Gains in productivity that are fundamental for economic growth should be based on an increase in workforce productivity, which can be achieved through reducing real salaries or through an effective reduction in the workforce (source of the first so-called economies of scale achieved with economic concentration). This movement is only made possible, however, via a high level of monopolization in the economy, which also creates great monopolistic conglomerates in the labour market. As previously mentioned, this state of affairs is explained not only by the fact that competitors in the relevant sector are scarce and hardly relevant, but also because, in such economies, the colonial monopolistic standard ensures that there is a lack of competition among economic sectors. Sectors with real economic dynamism, capable of accumulating capital and absorbing the labour force, are few and concentrated.

Monopolies therefore have 'a triple draining effect' on society's resources (labour market, consumers and other sectors). Through such an absolutely concentrated growth standard, it is possible to have capital accumulation and therefore productive investment that leads to growth. That said, such a growth standard requires, for its own existence, inverse income redistribution, with impoverishment (relative for employed workers and absolute for those who lose their jobs) of lower income groups and relative impoverishment of peripheral economic sectors.

Placing the spotlight on structures also implies that predominant sociological-individualistic explanations for underdevelopment are not accepted. These justifications are frequently incorporated into neo-institutional reasoning to explain underdevelopment and suggested solutions. Hence, according to these theories, the individual motivation of colonizers of Latin America and Asia (that is, colonial exploitation), different from that of immigrants to North America and Oceania, was reflected in the entire institutional structure of society. This kind of statement errs in being an understatement and overstatement at the same time. On the one hand, it 
exaggerates the differences in the individual spirit of colonizers. Interesting studies demonstrate that the colonial experience is richer than this distinction appears to suggest. Within the same colonies, there co-existed regions of mere exploitation with regions where colonizers considered settling and remaining. Both situations happened in colonized countries in Latin America, Asia and even Africa (South Africa, for example). In these countries, be they Argentina, Australia or India, the capitalist colonial spirit was similar. ${ }^{1}$

On the other hand, what these sociological-individualistic theories fail to consider is precisely the study of economic structures created by exploitive colonization. These structures, and not individual motivation, are the main factors that lead to differences between economies based on exploitive monopoly and societies in which these structures do not prevail. They end up determining economic cycles and influencing the whole of a society's socioeconomic system, prevailing over the similarities or differences that regions that experienced the definitive settling of populations, as opposed to those where populations were merely exploited, could have from the point of view of the motivations of explorers. Thus, regions of similar colonial spirit, such as Buenos Aires in Argentina and Sydney in Australia, result in countries and regions of social and economic development levels that are (or were) rather different.

Structural concentration of economic power therefore produces effects on the entire system, concentrating income between industrial sectors and between social strata. This concentration of power and income also causes economic growth patterns to change substantially. The increase is strongly based, among other factors, in productivity gains resulting from the inverse redistribution of income from workers (both employed and surplus) to the great conglomerates (and their small number of shareholders). ${ }^{2}$ 
This is not, however, just a history of ex-colonial economies. The globalization era of the final part of the twentieth century demonstrated that colonial economies were just a laboratory for structures that would prevail in economic systems throughout the whole world. So not only was the entire economic system of colonized regions affected by such structures and economic patterns, but in the long run the entire world economic system. As will be seen in Part 2 (Chapter 6), the more powerful the economic structures proved to be, the more chances they had to prevail in the global arena. So structures that were fed and grown in the ex-colonial economies and through favourable terms of trade made possible by the existence of such structures, gained strength and spread to all markets and most countries (both to the so-called underdeveloped as well as to the developed world).

Monopolies are not, however, just an economic phenomenon. They bring with them the social standards of exploited societies. Movement of factories around the world in a desperate search for cheap labour (be it child labour or labour used to destroy the environment) become common practices. Structural unemployment, poverty and exclusion in (once) developed countries follow.

As a consequence, at the end of the twentieth century, social characteristics of underdeveloped countries (mostly ex-colonies) tended to spread and eventually did spread to once developed countries. The final result seems to be a revenge of colonial past (and economic power structures formed during it), historically developing from a regionally restricted economic system of exploitation (during colonial times and industrial times until deep in the twentieth century) to become one of the main features of the functioning of present global markets (end of twentieth century and twenty-first century). The reality of monopolized markets and social and economic underdevelopment, ${ }^{3}$ once a phenomenon

3 It is important to state that it is not the purpose of this work to discuss concepts of development and underdevelopment, either through the use of Gini Indexes, or even HDI Index and/or their application or critical discussion. We are basically trying to discover common traits of underdevelopment due to economic (monopolistic) structures originated in the colonial past. In the historical analysis undertaken here, those traits are found in the existence of monopolies and their 'triple draining effects'. In other words, according to the historical analysis undertaken in this book, the existence of monopolies and the 
concentrated in the Southern Hemisphere, turn out to be a global one in the twenty-first century. ${ }^{4}$

This book will try to explore this vicious cycle and economic adverse selection between economic and social structures among all countries in economic and social history, first (Part 1) by critically discussing the prevailing economic, legal and philosophical thinking that still sustains and supports the existence of concentrated markets and concentrated economic power structures. They portray a real 'march of acceptance' of concentrated economic structures and help the diffusion of colonial-born structures (monopolies) to modern globalized markets. According to the view sponsored, it is this bulk of ideas that responds for the still prevailing concentration of development studies, both academic and non-academic (OCDE), on institutions (and institutional change) and not structures and structural change. ${ }^{5}$

complete draining of social and economic spheres operated by them are the historical signs of underdevelopment. The historical analysis of monopolies and triple draining effects will be the core of Part 2 of this book.

4 Such a global march to economic and social underdevelopment is a long-term process and of course it is difficult to prove it based on non-dynamic long-term analysis of both (so-called) developed as well as underdeveloped countries. Such analysis will probably just be fully consistent many decades from now, since convergence to underdevelopment is a relatively new process. Moreover, such convergence, today very clear in terms of monopoly's triple draining effects, will probably take decades to be revealed in traditional welfare or social development indexes (Gini or HDI). Having said that, it is important to notice that although not conclusive, the recent effort by T. Piketty (Le capital au XXIe siècle, Paris, Seuil, 2013) to demonstrate the growing concentration of capital mainly in (once) developed Northern Hemisphere countries is a first step to demonstrate the trend mentioned above in the text, especially if we take into account the concept of 'traits of underdevelopment' adopted here (see note 3 above). Indeed, concentration of capital higher than economic growth rates indicates clearly the existence of structures constantly capable of concentrating wealth at a bigger rate than the GDP growth, that is, it is clearly consistent with the 'triple draining effect' thesis. Unfortunately, the structural causes of wealth concentration seem not to be relevant in Piketty's analysis. This is in my opinion the main reason for the rather delusive and limited proposals of regulation of capital concentration presented in Part IV of his book. They do not even touch on or deal with the regulation, limitation or transformation of the economic structures responsible for wealth concentration.

5 There are many differences between the structural and institutional views. The central ones are in its definition and aims. Institutions are usually defined as those elements (norms, beliefs, culture and organizations) which are 
In Part 2 we will try to follow the historical development of concentrated economic structures (monopolies) from the colonial past to present global markets.

Finally, Part 3 will summarize conclusions and lessons from the previous historical analysis and suggest lines of study for structural transformations of societies - of course in a prospective, nonconclusive way.

directed or aimed at producing predictable behaviours from economic agents, making economic transactions easier and reducing transactions' costs - see A. Greif, 'Contract enforceability and economic institutions in early trade: the Maghribi trader's coalition' in American Economic Review, Vol. 83 (1993) pp. 525-48. Structures, on the other hand, are not aimed at creating predictable behaviour. Their ultimate objective is to concentrate resources and wealth through different forms of economic or legal monopolization of the economy see C. Salomão Filho, A legal theory of economic power - implications for social and economic development, Cheltenham, Edward Elgar, 2011, p. 2. 
Calixto Salomão Filho - 9781784718732

Downloaded from PubFactory at $04 / 26 / 2023$ 02:19:25PM

via free access 